\title{
Anabases
}

ANABASES Traditions et réceptions de l'Antiquité

26 | 2017

Varia

Patrick BAKER, Ronny KAISER, Maike PRIESTERJAHN, Johannes HELMRATH (éd.), Portraying the Prince in the Renaissance. The Humanist Depiction of Rulers in Historiographical and Biographical Texts

\section{Gaëlle Demelemestre}

\section{OpenEdition}

Journals

Édition électronique

URL : http://journals.openedition.org/anabases/6239

DOI : 10.4000/anabases.6239

ISSN : 2256-9421

Éditeur

E.R.A.S.M.E.

Édition imprimée

Date de publication : 1 novembre 2017

Pagination : 220-222

ISSN : 1774-4296

\section{Référence électronique}

Gaëlle Demelemestre, « Patrick baker, Ronny kaISer, Maike priesterJahn, Johannes helmRath (éd.)

Portraying the Prince in the Renaissance. The Humanist Depiction of Rulers in Historiographical and Biographical Texts », Anabases [En ligne], 26 | 2017, mis en ligne le 01 novembre 2017, consulté le 20 janvier 2021. URL : http://journals.openedition.org/anabases/6239; DOI : https://doi.org/10.4000/ anabases.6239

Ce document a été généré automatiquement le 20 janvier 2021.

(c) Anabases 


\title{
Patrick BAKER, Ronny KAISER, Maike PRIESTERJAHN, Johannes HELMRATH (éd.), Portraying the Prince in the
} Renaissance. The Humanist Depiction of Rulers in Historiographical and Biographical Texts

\author{
Gaëlle Demelemestre
}

\section{RÉFÉRENCE}

Patrick BAKER, Ronny KAISER, Maike PRIESTERJAHN, Johannes HELMRATH (éd.), Portraying the Prince in the Renaissance. The Humanist Depiction of Rulers in Historiographical and Biographical Texts, Berlin/Boston, de Gruyter, 2016, 489 p., 99, 95 euros/ISBN 978-3-11-047236-3.

1 L'ouvrage est le troisième tome d'une trilogie consacrée à l'historiographie humaniste. Il entreprend de réévaluer le paradigme classique des écrits historiques humanistes en étudiant plus précisément les procédés littéraires qu'ils mobilisent et l'intelligence que l'historien a de son art et de sa fonction. Les seize contributions, rédigées en langue anglaise ou allemande, sont précédées d'un résumé et suivies d'une bibliographie des sources et de la littérature adjacente spécialisée. Elles sont regroupées suivant les quatre angles d'étude retenus pour explorer l'historiographie humaniste: le genre propre du miroir des princes, les implications sociopolitiques de l'historiographie humaniste, ses relations aux antécédents antiques et médiévaux, et la question de la méthode mise en œuvre pour constituer un discours historiographique. Sont exposés des travaux de toute l'Europe humaniste, ce qui élargit d'autant la portée de ces études. 
2 La première partie de l'ouvrage est consacrée au thème des vertus princières. L'établissement du portrait du prince à la Renaissance requiert nécessairement d'en pointer les vertus. Les vertus cardinales de la tradition médiévale sont généralement reprises, mais avec le choix de certaines suivant les circonstances. En étudiant le portrait de CharlesVII dressé par l'historiographie française des $\mathrm{xV}-\mathrm{XVI} \mathrm{I}^{\mathrm{e}}$ siècles, T. Schwitter montre ainsi que l'accent porte moins sur la figure du roi en tant que tel, que sur l'idéal de l'ordonnance politique, qui garantit le bon ordre du royaume et la bonne organisation du personnel à son service. M. Priesterjahn souligne les réflexions sur le travail d'historien, la fonction du portrait du prince et la position de l'écrivain comme individu historique ressortant de la présentation par Paolo Emilio de Charlemagne. En adaptant les anciennes stratégies narratives et les catalogues médiévaux des vertus, Emilio opère une construction du prince médiéval soulignant les qualités directement pertinentes pour les rois de France actuels. S. Schlelein et $\mathrm{H}$. Schadee étudient plus précisément les stratégies littéraires utilisées par les historiens humanistes, le premier soulignant chez Polydore Virgile le rôle central des techniques utilisées pour portraiturer le prince, passant par une transformation des anciennes pratiques littéraires, la seconde montrant comment évolue le style du portrait à partir des quatre portraits d'Alfonso le Grand dressés par Bartolomeo Facio et Antonio Panormita.

3 La deuxième partie traite des prétentions culturelles, politiques et «nationalistes » de l'historiographie humaniste. L. Spoljaric montre comment les princes de Krk ont construit une généalogie identitaire à partir d'un mythe fondateur les reliant à la noblesse romaine pour légitimer la royauté croate. R. Kaiser analyse le discours historique mis en œuvre par Franciscus Irenicus pour accroître la fierté des Germains en en faisant des ancêtres de Noé. La présentation par F. Schaffenrath du récit épique de Riccardo Bartolini sur Maximilien signale l'importance de ce style littéraire dans le genre du portrait. En combinant les styles de l'Énéide de Virgile et de la Pharsale de Lucain, il façonne l'image d'un empereur se positionnant naturellement à la tête d'une campagne paneuropéenne contre les Turcs.

4 La troisième partie traite des relations entre les modèles historiographiques anciens, médiévaux et humanistes. Pour mieux faire ressortir la spécificité de la méthode humaniste, T. Haye étudie le panégyrique de Cosme deMédicis dressé par Giovanni Mari o Filelfo qui, malgré son intention de glorifier les Médicis, n'a pas eu d'impact, parce qu'il est resté trop proche du modèle classique sans s'adapter au contexte de la république florentine de l'époque. $W$. Strobl fait ressortir les intentions critiques envers la politique française de Louis XI en étudiant la façon dont Hilarion de Vérone fait de Charlemagne l'empereur universel au Moyen Âge et le protecteur des États du pape. L'étude de Jacobus Sluperius par M. Laureys met en évidence une hybridation des modèles humanistes et du monde médiéval, où est abordée la question de la licence poétique dans la biographie d'hommes militaires célèbres.

5 La quatrième partie traite de la question centrale de la méthode utilisée par l'historiographie humaniste, où la valeur et la place de la vérité dans les textes historiques sont travaillées. Les historiens se trouvent dans une position délicate. Que peut-on dire des princes dont la mémoire est encore vivante? Comment faire une place à la vérité lorsque l'on est historien de la Cour? Il ressort des contributions que l'ars historica prend son origine aux $\mathrm{XV}-\mathrm{XVI}^{\mathrm{e}}$ siècles, comme le montre plus particulièrement G. Ianziti. P. Baker aborde frontalement la question du travail d'historien en traitant du 
débat fameux qui a opposé Lorenzo Valla et Bartolomeo Facio, le premier estimant qu'il devait relater les faits et s'en tenir au devoir de vérité, le second lui opposant que le but de l'histoire est de glorifier les hauts faits des personnes célèbres, une vision plus adéquate aux attentes et représentations de l'époque. J. Keyser explore les questions relatives à la liberté de l'auteur et à sa possible sincérité dans un contexte où le poète se devait à des compromis pour obtenir le soutien de mécènes. Ch. Peters approfondit la relation entre discours épique et historiographie, montrant que le récit épique venait soutenir le discours lorsque la description des res gestae n'était pas souhaitable. K. Ostenfeld-Suske pointe les instruments donnés par Juan Páez de Castro pour construire la "meilleure histoire", en discutant, avec l'exemple de Charles, les relations entre savoir et légitimité, morale et choix des sources, et leur influence sur le savoir historique.

6 L'ensemble se clôt par une conclusion critique et synthétique très féconde de A. Schirrmeister sur la façon dont l'humanisme élabore la construction de la figure princière.

7 L'ensemble de l'ouvrage permet à la fois de comprendre les moyens utilisés par les humanistes pour construire un discours historique sur les puissants, les enjeux que soulevait leur travail et la compréhension qu'ils avaient de leur art. Avec ses deux index des noms et des lieux, cet ouvrage particulièrement riche fournit des ressources importantes pour la recherche scientifique.

\section{AUTEUR}

\section{GAËLLE DEMELEMESTRE}

IHRIM, UMR 5317 CNRS/ENS Lyon

gdemelemestre@gmail.com 